for the \% of work time missed. PtGA scores were higher than PhGA, in each group and gender.

Conclusion: At diagnosis, SpA patients perceive a slightly higher disease burden than assessed by Physicians. For PROs other than BASDAI, AxSpA reported a worse impact than $\mathrm{pSpA}$. Overall, women showed a higher disease impact than men.

References: [1]Michelsen B. et al. PLoS ONE 2015; 10(4): e0123582.

Disclosure of Interests: Rosario Foti Speakers bureau: Speaker bureau honoraria from Eli Lilly, Sanofi, MSD, Janssen, AbbVie, Bristol-Myers Squibb, Celgene, Roche, Consultant of: Consultancy fees from Eli Lilly, Sanofi, MSD, Janssen, AbbVie, BMS, Celgene, Roche, Gabriella Cardinale: None declared., Luisa Costa: None declared., Franco Franceschini: None declared., Francesco Ciccia Speakers bureau: Speaker bureau honoraria from AbbVie, Abiogen, Bristol-Myers Squibb, Celgene, Janssen, Eli Lilly, Pfizer, Novartis, Roche, Consultant of: Consultancy fees from Novartis, Pfizer, Janssen, Eli Lilly, Roche, Celgene, Grant/research support from: Grant/research support from Pfizer, Novartis, Celgene, Janssen, Roche, Antonio Marchesoni: None declared., Giuliana Guggino Speakers bureau: Speaker bureau honoraria from Celgene, Sandoz, Pfizer, Grant/research support from: Grant/research support from Pfizer, Celgene, Maurizio Rossini: None declared., Ennio Lubrano Di Scorpaniello: None declared., Bruno Frediani: None declared., Maria Sole Chimenti: None declared., Gerolamo Bianchi: None declared., Giuseppe Galfo: None declared., Silvia Marelli Employee of: Employee of Janssen-Cilag SpA Italy, Ennio Favalli Speakers bureau: Consulting fees and/or speaking engagements from AbbVie, Bristol-Myers Squibb, Lilly, Merck Sharp \& Dohme, Pfizer, Galapagos, Sanofi-Genzyme, and UCB.

DOI: 10.1136/annrheumdis-2021-eular.624

\section{AB0489 \\ CORRELATION BETWEEN DISEASE ACTIVITY AND SERUM TNF-ALPHA LEVELS IN PATIENTS WITH ANKYLOSING SPONDYLITIS}

K. Kraev ${ }^{1,2}$, M. Geneva-Popova ${ }^{1,3}$, S. Popova ${ }^{1,3} .{ }^{1}$ Medical University Plovdiv, Propedeutics of Internal Diseases, Plovdiv, Bulgaria; ${ }^{2}$ Multiprofile Hospital for Active Treatment "Kaspela", Rheumatology, Plovdiv, Bulgaria; ${ }^{3}$ Multiprofile Hospital for Active Treatment "St.George", Rheumatology, Plovdiv, Bulgaria

Background: Ankylosing spondylitis (AS) is an immune-mediated rheumatic disease, it belongs to the spectrum of the axial spondyloarthritis. Several elements are important for the pathogenesis of AS - they include interactions in the context of a specific genetic origin between the intestinal microbiome, innate immunity, lymphoid cells and anatomical structures, which are the entheses of the axial skeleton and peripheral joints. The main mediators of the inflammatory process are TNF - $\alpha$, IL-17 and IL-17A.

Objectives: To study the level of TNF-alpha in the serum of patients with ankylosing spondylitis and to assess its relationship with the indices of disease activity before starting therapy with TNF-alpha blockers and in the dynamics after initiation of treatment.

Methods: The present study included 50 patients with ankylosing spondylitis and 31 healthy controls similar in age, sex, and BMI. Clinical and non-clinical methods of examination and evaluation were used for proper assessment and follow-up of patients. The disease activity indices that were used were BASDAI and ASDAS. Statistical analysis was performed with the IBM SPSS program, v.24., To prove the relationship between the level of TNF-alpha in the serum of patients and disease activity, a correlation analysis of Spearman Rho was used. Results: The level of TNF- $\alpha$ in patients with AS was highest before treatment initiation with biologics, $89.77 \pm 36.89 \mathrm{pg} / \mathrm{ml}$, and was significantly higher than that of healthy controls. At the next visit, the TNF- $\alpha$ level decreased to $27.59 \pm 23.88$ $\mathrm{pg} / \mathrm{ml}$, the difference being significant from baseline. 24 months after initiation of treatment with biological therapy average level of TNF- $\alpha$ in patients with AS did not differ reliably from its levels in 6 and 12 month after initiation of treatment, respectively, $22.36 \pm 22.38 \mathrm{pg} / \mathrm{ml}, 19,29 \pm 21.07 \mathrm{pg} / \mathrm{ml}$. The level of this cytokine significantly correlates with the activity of the disease, measured by the activity indices BASDAI, ASDAS.

Conclusion: The level of the pro-inflammatory cytokine TNF-alpha is significantly higher in patients with ankylosing spondylitis and significantly correlates with the disease activity in them, measured by the respective indices (BASDAI, ASDAS).

\section{REFERENCES:}

[1] Arends S., N. Lebbink, A. Spoorenberg et al., "The formation of autoantibodies and antibodies to TNF- $\alpha$ blocking agents in relation to clinical response in patients with ankylosing spondylitis", Clin Exp Rheumatol, 2010, 28: 661- 668.

[2] Bal A., E. Unlu, G. Bahar et al., "Comparison of serum IL-1 beta, sIL-2R, IL-6, and TNF-alpha levels with disease activity parameters in ankylosing spondylitis." Clin Rheumatol, 2007, 26: 211-215.

Disclosure of Interests: None declared.

DOI: 10.1136/annrheumdis-2021-eular.931

\section{AB0490 IMPACT OF SPONDYLOARTHRITIS ON WORK PRODUCTIVITY: A REAL LIFE STUDY}

M. Ben Majdouba ${ }^{1}$, S. Boussaid ${ }^{1}$, S. Rekik ${ }^{1}$, S. Jemmali ${ }^{1}$, H. Ajlani ${ }^{1}$, H. Sahli ${ }^{1}$ M. Elleuch'. ' 'La Rabta hospital, Rheumatology, Tunis, Tunisia

Background: Work productivity of patients with spondyloarthritis is frequently affected by their disease.

Objectives: We aim to identify disease-related factors associated with poor work productivity in patients with spondyloarthritis.

Methods: A cross-sectional study was performed in patients with spondyloarthritis. Data on disease characteristics were collected as well as specific indices: Visual analogue scale (VAS) for fatigue and pain, Bath Ankylosing Spondylitis Disease Activity Index (BASDAI), Ankylosing Spondylitis Disease Activity Score with CRP (ASDAS-CRP), Bath Ankylosing Spondylitis Functionnel Index (BASFI) and Bath Ankylosing Spondylitis Metrology Index (BASMI). EuroQol-5D (EQ5D) was used to assess health-related quality of life. Work productivity was assessed by the Work Productivity and Activity Impairment scale (WPAI:SpA). Factors associated with presenteeism, absenteeism and work productivity loss were evaluated. Results: One hundred patients were enrolled ( 73 men and 27 women); mean age was $43.68 \pm 10.3$ years. Fifty nine percent of patients were employed, $26 \%$ were off work and $15 \%$ were retired of which $8 \%$ were in early retirement. Sixty seven percent of patients had ankylosing spondylitis, $17 \%$ had rheumatism associated with inflammatory bowel disease and $16 \%$ had psoriatic rheumatism. The average disease duration was $12.24 \pm 8.73$ years. Mean age at onset was 33.2 \pm 10 years [18-59]. The average diagnostic delay was $2.41 \pm 3$ years; it was more than five years in $17 \%$ of cases. Sacroiliac pain has been noted in 69 patients lumbar or cervical stiffness in 78 patients and peripheral joint involvement in 18 cases. Thirty one percent of patients had hip joint involvement and $49 \%$ had extra-articular manifestation. Fifty percent had inflammatory biological syndrome $63 \%$ were treated with anti-TNF $\alpha$ and $58 \%$ needed symptomatic treatment regularly. The mean fatigue and pain VAS was respectively $5.58 \pm 2.5$ and $5.56 \pm$ 2.9. The mean BASDAI was $4.4 \pm 2.4$, the average BASFI was $4.6 \pm 2.7$ and the average ASDAS-CRP was $2.77 \pm 1$. 18 . The mean BASMI was $4.4 \pm 2.8$. The mean EQ5D score was $0.485 \pm 0.378$. Among employed patients, mean absenteeism, presenteeism and work productivity loss was $21.8 \pm 33.13 \%, 42 \pm 32 \%$ and $46.5 \pm 35.31 \%$, respectively. These work outcomes were correlated to diagnostic delay $\geq 2$ years $(p<0.03)$, peripheral joint involvement $(p=0.006)$, psoriasis $(p=0.02)$, inflammatory biological syndrome $(p<0.001)$, need of symptomatic treatment $(p=0.001)$, fatigue and pain VAS $\geq 4(p<0.001), B A S D A I \geq 4(p<0.001)$, ASDAS-CRP $\geq 2.1(p<0.001)$, BASFI $\geq 4(p<0.001)$, BASMI $\geq 4(p=0.002)$ and low EQ5D score $(p<0.001)$. Work productivity loss was in addition correlated to age at onset $<25$ years $(p=0.03)$

Conclusion: Active disease, reduced physical function and poorer quality of life are associated with reduced work productivity. Early diagnosis and good disease management especially fatigue and pain can potentially improve work outcomes in patients with spondyloarthritis.

Disclosure of Interests: None declared.

DOI: 10.1136/annrheumdis-2021-eular.1079

\section{AB0491 THE IMPORTANCE OF MUSCULOSKELETAL SYMPTOM QUESTIONING IN INFLAMMATORY BOWEL DISEASES}

B. Farisoğulları ${ }^{1}$, O. Keskin ${ }^{2}$, B. Usta ${ }^{3}$, G. K. Yardımcı ${ }^{1}$, E. Parlak ${ }^{2}$, T. Kav ${ }^{2}$ U. Kalyoncu ${ }^{1}$, O. Karadag ${ }^{1} .{ }^{1}$ Hacettepe University, Faculty of Medicine, Department of Internal Medicine, Division of Rheumatology, Ankara, Turkey; ${ }^{2}$ Hacettepe University, Faculty of Medicine, Department of Internal Medicine, Division of Gastroenterology, Ankara, Turkey; ${ }^{3}$ Hacettepe University, Faculty of Medicine, Department of Internal Medicine, Ankara, Turkey

Background: Spondyloarthritis (SpA) occurs in up to $13 \%$ of patients with inflammatory bowel disease (IBD) (1). Early diagnosis and treatment of SpA in IBD patients prevents irreversible musculoskeletal diseases.

Objectives: The aim of this study is to emphasize the importance of questioning musculoskeletal symptoms in patients with IBD.

Methods: In the Hacettepe University Gastroenterology Clinic, patients with IBD were questioned for musculoskeletal symptoms between March 2019 and September 2020. For this purpose, a validated DETAIL questionnaire (2) consisting of six questions was asked (1. Have you ever had a finger or a toe and/or another joint swollen and painful for no apparent reason? 2. Occasionally, has an entire finger or toe becomes swollen, making it look like a 'sausage'? 3. Have you had pain in your heels? 4. Have you ever had back pain lasting at least 3 months that was not injury related? 5 . Do you have low back pain in the morning and/or after resting that improves with exercise? 6 . Do you wake up at night because of low back pain?). Patients with at least 1 positive out of 6 questions were consulted in the rheumatology clinic, and patients were evaluated for SpA by physical examination, laboratory, and imaging. Demographic and clinical characteristics of IBD patients with and without SpA were compared. 
Results: 217 IBD patients were included in the study. Twenty patients with previously known rheumatologic diseases were excluded from the study. 49 (24\%) of the remaining 197 patients had a positive answer to at least one question in the DETAIL query. $39(20 \%)$ of these patients were evaluated in the rheumatology clinic, and $16(8.1 \%)$ of them were diagnosed with SpA (spondylitis: 9, peripheral arthritis: 7) (Figure 1). There were no significant differences in terms of age, gender, IBD type, duration of IBD, current treatment, fibromyalgia syndrome (FMS) and depression according to Beck depression inventory between patients with IBD with and without SpA (Table 1).

Table 1. Clinical, demographic characteristics of the IBD patients according to SpA.

\begin{tabular}{|c|c|c|c|}
\hline & $\begin{array}{l}\text { IBD with SpA } \\
n=16\end{array}$ & $\begin{array}{l}\text { IBD without SpA } \\
n=23\end{array}$ & $\mathbf{p}$ \\
\hline Age, years, median (IQR) & $47.03(27.4)$ & $35.9(14.1)$ & 0.052 \\
\hline Female, n (\%) & $8(50)$ & $17(74)$ & 0.12 \\
\hline \multicolumn{4}{|l|}{ IBD type, $\mathrm{n}(\%)$} \\
\hline CD & $6(37)$ & $11(48)$ & 0.19 \\
\hline UC & $9(56)$ & $12(52)$ & \\
\hline IC & $1(7)$ & & \\
\hline Smoking (ever), n (\%) & $10(62.5)$ & $11(48)$ & 0.37 \\
\hline HLA-B27 positivity, n (\%) & $2(12.5)$ & $1(4.3)$ & 0.57 \\
\hline \multicolumn{4}{|l|}{ Current medication, n (\%) } \\
\hline - Steroid (oral and/or topical) & $6(37.5)$ & $5(21.7)$ & 0.31 \\
\hline - 5-ASA & $11(68.8)$ & $14(61)$ & 0.61 \\
\hline - Immunosuppressants (AZA, MTX) & $6(37.5)$ & $8(34.8)$ & 0.86 \\
\hline - bDMARD & $2(12.5)$ & $4(17.4)$ & 1 \\
\hline FMS, n (\%) & $1(6.7)$ & $3(13)$ & 1 \\
\hline \multicolumn{4}{|c|}{ Beck depression Inventory, level of depression, $n(\%)$} \\
\hline -minimal & $1(9)$ & $5(22)$ & 0.13 \\
\hline -mild & $8(73)$ & $7(30)$ & \\
\hline -moderate & $2(18)$ & $9(39)$ & \\
\hline -severe & 0 & $2(9)$ & \\
\hline
\end{tabular}

Harvey-Bradshaw Index for CD disease activity and Mayo score for UC disease activity were used.SD: standard deviation, IQR: inter-quartile rangeIBD: inflammatory bowel disease; SpA: Spondyloarthritis, bDMARD: biological disease modifying anti-rheumatic drug, CD: Crohn's disease, UC: Ulcerative colitis, IC: indeterminate colitis; HBI: Harvey-Bradshaw Index ASA: 5-aminosalicylic acid; AZA: azathioprine; MTX: methotrexate; FMS: Fibromyalgia syndrome

Conclusion: By questioning the musculoskeletal system in IBD patients, $20 \%$ of the patients were evaluated in the rheumatology department, and nearly half of these patients (8\%) were diagnosed with SpA. The findings point to the importance of musculoskeletal symptom questioning in routine outpatient clinic control in IBD patients. REFERENCES:

[1] Karreman MC et al. The prevalence and incidence of axial and peripheral spondyloarthritis in inflammatory bowel disease: a systematic review and meta-analysis. Journal of Crohn's and Colitis, 2017, 11.5: 631-642.

[2] Di Carlo $\mathrm{M}$ et al. The DETection of Arthritis in Inflammatory boweL diseases (DETAIL) questionnaire: development and preliminary testing of a new tool to screen patients with inflammatory bowel disease for the presence of spondyloarthritis. Clinical rheumatology, 2018, 37.4: 1037-1044

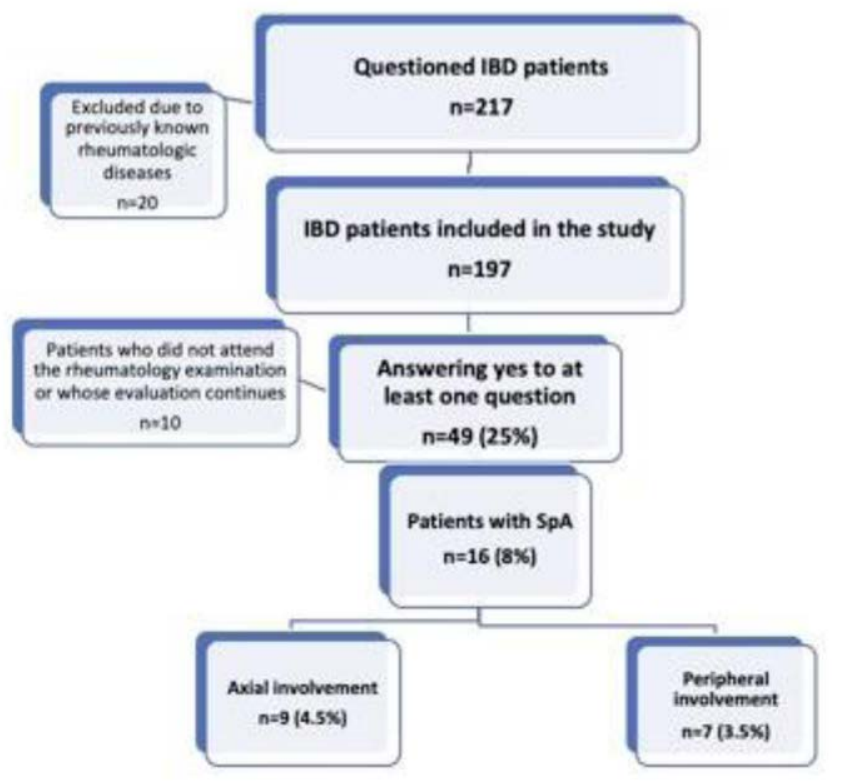

Figure 1 Flow chart of IBD patients in the study
Disclosure of Interests: None declared.

DOI: 10.1136/annrheumdis-2021-eular.1232

\begin{tabular}{l|l}
\hline AB0492 & DETERMINING FACTORS RELATED TO \\
POOR QUALITY OF LIFE IN PATIENTS WITH \\
SPONDYLOARTHRITIS: A REAL LIFE STUDY
\end{tabular}

M. Ben Majdouba ${ }^{1}$, S. Boussaid ${ }^{1}$, S. Rekik ${ }^{1}$, S. Jemmali ${ }^{1}$, H. Ajlani ${ }^{1}$, H. Sahli ${ }^{1}$, M. Elleuch ${ }^{1} .{ }^{1}$ La Rabta hospital, Rheumatology, Tunis, Tunisia

Background: When treating people with spondyloarthritis (SA), rheumatologists are focused on reducing disease activity based on activity measurement scores; but there may be other factors not directly captured by these tools, which impact on quality of life.

Objectives: We aim to identify factors associated with poor quality of life in patients with spondyloarthritis.

Methods: A cross-sectional study was performed in 100 patients with spondyloarthritis. Data on sociodemographic and disease characteristics were collected as well as specific scores: Visual analogue scale (VAS) for fatigue and pain, Bath Ankylosing Spondylitis Disease Activity Index (BASDAI), Ankylosing Spondylitis Disease Activity Score with CRP (ASDAS-CRP), Bath Ankylosing Spondylitis Functionnel Index (BASFI) and Bath Ankylosing Spondylitis Metrology Index (BASMI). EuroQol-5D (EQ5D) was used to assess health-related quality of life.

Results: A total of 100 Patients were enrolled (73 men and 27 women); the mean age was $43.68 \pm 10.3$ years. Thirteen percent of patients had high level of education (>12 years), $47 \%$ had $\mathrm{BMI} \geq 25$ and $47 \%$ were smoking. Sixty seven percent of patients had ankylosing spondylitis, $17 \%$ had rheumatism associated with inflammatory bowel disease and $16 \%$ had psoriatic rheumatism. The average disease duration was $12.24 \pm 8.73$ years. Mean age at onset was 33.2 \pm 10 years. The average diagnostic delay was $2.41 \pm 3$ years. Sacroiliac pain has been noted in 69 patients, lumbar or cervical stiffness in 78 patients and peripheral joint involvement in 18 cases. Thirty one percent of patients had hip joint involvement and $49 \%$ had extra-articular manifestation. Fifty percent had inflammatory biological syndrome, $63 \%$ were treated with anti-TNF $\alpha$ and $58 \%$ needed symptomatic treatment regularly. The mean fatigue and pain VAS was respectively $5.58 \pm 2.5$ and $5.56 \pm 2.9$. The mean BASDAI was $4.4 \pm 2.4$, the average BASFI was $4.6 \pm 2.7$ and the average ASDAS-CRP was $2.77 \pm 1.18$ The mean BASMI was $4.4 \pm 2.8$. EQ5D questionnaire showed that: 37 patients had no problems with mobility, 61 had some problems and two had extreme problems; 39 patients had no problems with self-care, 55 had some problems and six had extreme problems; 35 patients had no problems with performing usual activities, 60 had some problems and five had extreme problems; 13 patients had no pain or discomfort, 61 had moderate pain or discomfort and 26 had important pain or discomfort; 42 patients had no anxiety or depression, 46 had moderate anxiety or depression and 12 had extreme anxiety or depression. The mean EQ5D score was $0.485 \pm 0.378[-0,448-1]$ and the mean general health EQ5D VAS was $59 \pm 25 \%$ [7-100]. Poor quality of life was associated with smoking $(p=0.03)$, physical inactivity $(p<0.001)$, cervical and lumbar stiffness $(p=0.001)$, peripheral joint involvement $(p=0.006)$, inflammatory biolog ical syndrome $(p<0.001)$, need of symptomatic treatment $(p<0.001)$, BASDAI $>4(p<0.001)$, ASDAS $>2.1(p<0.001)$, BASFI $>4(p<0.001)$ and BASMI $>4$ $(\mathrm{p}<0.001)$.

Conclusion: Active disease and reduced physical function are the main causes of poor quality of life in patients with spondyloarthritis. Good disease management, smoking cessation and encouragement of physical activity can potentially improve patients' quality of life.

Disclosure of Interests: None declared.

DOI: 10.1136/annrheumdis-2021-eular.1269

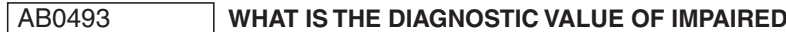 SPINAL MOBILITY MEASUREMENTS IN INFLAMMATORY BACK PAIN PATIENTS? DATA FROM THE DESIR COHORT}

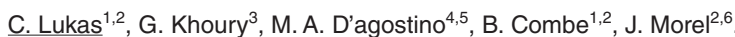
${ }^{1}$ University Montpellier, IDESP, Montpellier, France; ${ }^{2}$ University hospital Montpellier, Rheumatology, Montpellier, France; ${ }^{3}$ University hospital Montpellier, rheumatology, Montpellier, France; ${ }^{4}$ University Paris Ouest-Versailles-SaintQuentin-en-Yvelines, Rheumatology, Boulogne Billancourt, France; ${ }^{5}$ Ambroise Pare Hospital, Rheumatology, Boulogne Billancourt, France; ${ }^{6}$ University Montpellier, IGMM, Montpellier, France

Background: The diagnostic process in a patient with early inflammatory back pain suggestive of axial spondyloarthritis (ax-SpA) requires assessment and integration of multiple aspects, including clinical examination, biologica measurements and radiologic assessments. Among the physical examination features, alteration of spinal mobility is often observed in ax-SpA. However, 